\title{
The Effect of Aquatic and Dryland Resistance Training on Peroxisome Proliferator Activated Receptor-a Gene Expression in Middle-aged Women's Peripheral Blood Mononuclear Cell after Coronary Artery Bypass Grafting
}

\author{
${ }^{1}$ Leili Zeiaadini Dashtkhaki, ${ }^{2}$ Amir Rashid Lamir ${ }^{*}{ }^{3}$ Saeed Naghibi \\ ${ }^{1}$ Department of Sport Science, Neyshabur Branch, Islamic Azad University, Neyshabur, Iran. ${ }^{2}$ Department of \\ Exercise Physiology, Faculty of Sport Science, Ferdowsi University of Mashhad, Mashhad, Iran. ${ }^{3}$ Department of \\ Exercise Physiology, University of Payame Noor, Tehran, Iran.
}

\begin{abstract}
Background. Cardiac rehabilitation program is aimed at reducing secondary risk factors and improving function in patients undergoing coronary artery bypass grafting run which ultimately may delay or reduce mortality in patients. A major component of cardiac rehabilitation program is exercise. Objective(s). This study is aimed at evaluating the effect of aquatic and dryland training on Peroxisome Proliferator Activated Receptor-a (PPAR- $\alpha$ ) gene expression in middle-aged women's peripheral blood mononuclear cells (PBMNCs) after coronary artery bypass grafting. Methods. Thirty middle-aged women with cardiovascular disease were categorized into three groups comprising control (CON), aquatic resistance training (ART) and dryland resistance training (DRT). The dryland training program lasted for eight weeks of resistance training (3 sessions per week/ 60 minutes per session) and included two to three sets of $12-15$ repetitions with $60 \%$ of $1 \mathrm{RM}$. The aquatic resistance training lasted for eight weeks (3 sessions per week/ 60 minutes per session), with 60 to $80 \%$ of 1RM for each exercise primarily. Fasting blood samples were taken from all participants 48 hours both before the beginning of the training program and after the last training session. PPAR $\alpha$ relative gene expression was identified by Real-Time PCR method. Results. It is showed a significant increase in the relative PPARa gene expression in both aquatic and dryland resistance training groups $(\mathrm{F}=15.573, \mathrm{P}=0.001)$. It is found a significant difference in aquatic and dryland resistance training groups as regards PPARa gene expression $(\mathrm{P}=0.001, \mathrm{t}=-6.954 ; \mathrm{P}=0.001, \mathrm{t}=-5.871$; respectively). Conclusion. The results revealed that both of them on land and water training, increase PPARa gene expression in middle-aged women after coronary artery bypass and a possible reverse cholesterol transport process can be improved, so it is recommended that this type of training program, cardiac rehabilitation should be employed.
\end{abstract}

KEY WORDS: PPAR- $\alpha$, Exercise Training, Coronary Artery Bypass Grafting, Peripheral Blood Mononuclear Cells.

\section{INTRODUCTION}

Cardiovascular diseases are the primary cause of death and disability in the world $(1,2)$.
Coronary artery disease refers to the complete or partial narrowing or blockage of the coronary

*. Corresponding Author:

Amir Rashid Lamir

E-mail: rashidlamir@um.ac.ir 
artery due to atherosclerosis, spasm or thrombosis, in which it is impossible to provide myocardial muscle with oxygen, thereby resulting in angina and heart attack (3). Coronary artery bypass grafting $(\mathrm{CABG})$ is a type of treatment in which the coronary blood flow increases through a bypass created by linking the areas before and after the blockage in the coronary arteries (4). In fact, only coronary artery bypass grafting can guarantee the survival of ischemic patients when medical treatment proves ineffective (5). Related studies indicated that approximately 35,000 to 50,000 heart surgeries are performed in Iran annually (6).

One of the causes of cardiovascular disease is changes in fatty acid balance (Homeostasis). It was shown that the effect of fatty acids is exerted through binding to soluble nuclear receptors and regulating of genes expression (7). Peroxisome proliferator activated receptors (PPARs) are among the most important nuclear receptors playing a vital role in obesity-related metabolic diseases such as hyperlipidemia, insulin resistance, and coronary artery diseases, and controlling fat homeostasis by regulating the expression of the genetic networks involved in metabolism, transport, storage and disposal of fat $(8,9)$. Regarding the effect of PPAR gene expression in atherosclerotic lesions and the down-regulation of multiple atherogenic genes, it has been suggested that the stimulation of PPAR expression or activity may have a beneficial effect on atherosclerotic disease process (9) and mainly control cellular metabolism (carbohydrate, fat and protein) and cellular differentiation (10). There are three isotopes of PPAR, called PPARa, PPAR $\beta / \delta$ and $\operatorname{PPAR} \gamma$, whose distributions vary in different tissues (8). PPAR $\alpha$, which is expressed in the liver, heart, muscle, and kidney (9), regulates the transcription of some genes involved in the oxidation of cardiac fatty acids (11). The effect of PPAR agonists on the up-regulation of ATP binding cassette type A (ABCA1) has been scientifically confirmed (12). As a member of the large ATP binding cassette (ABC) family, (13) ABCA1 is essential for transmitting lipids through plasma membrane and maintaining the desirable HDL-C levels (14). These mechanisms can partly protect biological cells against cholesterol build-up. However, the modern lifestyle, automation resulting in lack of physical activity, high-fat diets, changes in body composition, muscle strength and functional capacity have increased the risk of coronary artery diseases (CAD) requiring coronary artery bypass grafting (15). Cardiac rehabilitation is one of the most important measures for increasing the effectiveness and decreasing the complications of heart surgeries (16). Cardiac rehabilitation programs aim at limiting physicalpsychological effects of cardiovascular disease, reducing the risk of sudden death or recurrent stroke, controlling cardiac symptoms, stabilizing and reversing the atherosclerotic process and improving psychosocial status (17). The impacts of exercise on cardiac rehabilitation have been highlighted during the recent decades (18). The low cost and attractiveness of these exercises can motivate patients to partake in cardiac rehabilitation programs (19). Traditionally, exercises performed in cardiac rehabilitation programs are mainly aerobic in nature, and include walking, jogging or biking. Researchers have recently discovered that resistance training can also be beneficial in rehabilitation programs. Furthermore, America Heart Association has recommended that resistance training should be included in cardiac rehabilitation programs twice a week (20). Based on previous studies on aquatic exercises, patients suffering from cardiovascular diseases claim to avoid swimming owing to adverse cardiorespiratory changes during swimming. It has also been reported that even light swimming can cause maximum oxygen consumption and heart rate overreactions particularly in patients with poor swimming skills. However, based on recent studies, the activities during which the head is kept above water- including walking in water or modified water games at appropriate temperatures- can be suitably low risk exercises for patients with coronary artery diseases. These activities motivate the patients further to carry out these exercises and optimize the anticipated cardiovascular adaptations resulting from exercising. Water sports- apart from swimmingwhich are done in upright positions and follow the principles are harmless activities, positively producing hemodynamic responses (20). Aquatic training is a comprehensive treatment approach designed to aid rehabilitation in different states 
and to increase patients' self-confidence (21). Invasive procedures employed for treating cardiovascular diseases can undermine patients' physical, emotional and mental strength. Therefore, an approach with recreational and refreshing properties as well as treatment would be welcomed by patients (22). Although the use of hydrotherapy has increased dramatically during the past two decades owing to its impressive benefits (23), inadequate attention has been paid to the effects of aquatic training on cardiovascular diseases, thus leading to a notable absence of research in the field of aquatic resistance training (20). Some researchers have recently focused on the effects of PPARs activities on fat metabolism $(24,25)$ and studied the relationship between physical activities and PPARs gene expression. However, most of these studies were carried out on healthy subjects $(26$, 27) or animal models (28, 29), and mainly examined aerobic exercises and reported different results $(26,28,29)$. In one study, Chen et al. (2014) reported a significant increase in PPAR- $\delta$ gene expression in skeletal muscles (vastus lateralis) after ten weeks of progressive resistance training in young men and women (30). In another study, Chen et al. (2016) found increased levels of PPAR- $\delta$ in skeletal muscles after single-session resistance training in young men and women (31). Regarding the relationship between reverse cholesterol transport (RCT) and cardiovascular diseases, the positive effect of physical activities on key factors affecting this process $(14,28,32,33)$ and the role of cardiac rehabilitation in limiting mental and physical effects of the disease, it appears that studying the factors involved in this process- especially the expression of genes and their regulatory mechanisms- can contribute to the prevention or more effective treatments of cardiovascular diseases. In addition, studies on the effects of rehabilitation on cardiac patients can evidently provide us with new information as well as new ways of decreasing mortality in cardiac patients after coronary bypass grafting. There has only been limited research on the effect of aquatic resistance training on reverse cholesterol transport (20) with a noticeable gap in studies which focus on the effects of such trainings on the expression of genes in patients who have undergone $\mathrm{CABG}$. As a pioneering research in the field of cardiac rehabilitation, the current study is aimed at examining PPAR $\alpha$ gene expression in peripheral blood mononuclear cells (PBMNCs) in middle-aged women having had $\mathrm{CABG}$, after 8 weeks of aquatic and dryland resistance training programs.

\section{MATERIALS AND METHODS}

Participants. The statistical population of the present study comprised middle-aged female patients who had undergone coronary artery bypass previously and were referred to Shafa Hospital in Kerman. Thirty volunteers (aged 4356 years) who met the inclusion criteria were selected for this study from the entire population.

Patients were excluded from this study if they had unstable angina, decompensated heart failure, and myocardial infarction within the last month, problematic ventricular arrhythmias (15) or any other limitations examined by the doctor. After initial clinical assessment and evaluation of the severity and extent of the heart disease by a physician, patients were included in the study if they had already had coronary bypass, had a homogeneous level of the disease, were relatively fit to carry out the exercises and had undergone coronary artery bypass between 3 months to 3 years before the study. Following a random screening, the participants were divided into control group $(\mathrm{CON})(\mathrm{n}=10)$, the aquatic resistance training group (ART) $(\mathrm{n}=10)$ and dryland resistance training group (DRT) $(n=10)$. The basic anthropometric characteristics of the subjects are described in Table 1.

Table 1. Sample size and basic characteristics of subjects in each group (mean \pm standard deviation)

\begin{tabular}{cccc}
\hline $\begin{array}{c}\text { Variables } \\
\text { Groups }\end{array}$ & Weight (kg) & Age (yrs.) & Height (m) \\
\hline Dryland resistance training & $81.1 \pm 9.50$ & $49.9 \pm 4.14$ & $155.7 \pm 2.26$ \\
Aquatic resistance training & $79 \pm 10.48$ & $50.2 \pm 3.61$ & $159 \pm 6.09$ \\
Control group & $72 \pm 10.26$ & $49.6 \pm 4.06$ & $158.8 \pm 4.82$ \\
\hline
\end{tabular}


Dryland training program. Dryland training program included eight weeks of resistance training ( 3 days a week /60 minutes per session) and consisted of warm-up (10 minutes), main activity (30 to 40 minutes) and cooling down (10 minutes). One-repetition maximum for subjects was determined using the formula (onerepetition maximum=amount of weight $/[1.0278$ $-(0.0278 \times$ the number of repetitions)] (34). Afterwards, the 8-session main activity was performed. It included machine bench press, seated cable row, inner thigh movements, Lat pulldown, pec deck, outer thigh movements, curl-ups, and hyper-extension with 2-3 sets of 12-15 repetitions with $60 \%$ of one-repetition maximum. There were 30-second rests between exercises, and 5-minute rests between sets. Onerepetition maximum test was repeated at the end of the fourth week in order to adjust the training protocol to the changes. According to the results obtained through this test, the training protocol continued until the end of the eighth week (20).

Aquatic resistance training. Aquatic training took place in a shallow pool $(120 \mathrm{~cm}$ deep) at a temperature between $28-30^{\circ} \mathrm{C}$. Aquatic training exercises (with 60 to $80 \%$ of onerepetition maximum for each exercise) lasted for 8 weeks ( 3 sessions per week/ 60 minutes per session) and included a warm-up (10 minutes), main activity (30-40 minutes) and cooling down (10 minutes). The main activity comprised 3 sets of upper-body dumbbell exercises including: shoulder shrugs, shoulder horizontal extension, shoulder extension with external rotation, and shoulder press with rotation, and lower body exercises with ankle weights including standing leg curls, supported squats, inner and outer thigh abduction, and sliding backward and forward with partial to full ranges of motion, with 8 repetitions during the first four weeks, and 10 repetitions during the $5^{\text {th }}$ to $8^{\text {th }}$ weeks. The training program of each session is different from other sessions, and was based on the principles of kinesiology, exercise science (20).

RNA, cDNA Synthesis. $10 \mathrm{ml}$ of fasting blood samples were taken from brachial veins of subjects in all three groups 48 hours both prior to the beginning of the training program and after the last training session. The samples were collected in a test tube with EDTA anticoagulant and transferred to the laboratory. After the isolation of mRNA of PBMN cells (14), the synthesis of cDNA was done using $200 \mathrm{ng}$ of mRNA, primers oligo (dT) and Kit (Fermentas $\mathrm{GmbH}$, which was made in Germany). RealTime-PCR method was employed to investigate the expression of PPAR a. Table 2 illustrates the sequence of PPAR a primers (27) and Beta-actin (14).

Table 2. Oligo nucleotide sequences of primers

\begin{tabular}{ccc}
\hline Gene & Type & Primers sequence \\
\hline PPAR a & $\begin{array}{l}\text { forward } \\
\text { Reverse }\end{array}$ & $\begin{array}{c}\text { tgaacgatcaagtga cat tgc } \\
\text { tgggaa gag aaa gat atc g }\end{array}$ \\
\hline B-Actin & $\begin{array}{l}\text { forward } \\
\text { reverse }\end{array}$ & $\begin{array}{c}\text { cctatgttctcagcagcttc } \\
\text { gaatttcctggctgt ccc tg }\end{array}$ \\
\hline
\end{tabular}

Real-Time PCR. Polymerase chain reaction was performed by BIO RAD (C1000 TM Thermal Cycler) in microplates with 96 wells Real Time PCR which was run to measure the level of gene expression and the parameters for a two-step PCR were $95^{\circ} \mathrm{C}$, for $5 \mathrm{~min}, 1$ cycle, then $95^{\circ} \mathrm{C}$, for 10 seconds and then $60{ }^{\circ} \mathrm{C}$, for 30 seconds, 45 cycles and parameters for melting curve program were 55 to 95 (incremented 0.5 for f seconds) (35).

Statistical Analysis. The number of copies of the target and reference genes was measured by using cycle threshold (36). The data were then analyzed using descriptive and inferential statistics. Owing to the normal distribution of data in Shapiro-Wilk test, analysis of covariance was used to determine the differences between groups, whereas paired-samples t-test was used to find the differences within groups (SPSS version 16), with the significance level set at $\mathrm{p}<0.05$.

\section{RESULTS}

The results revealed a significant increase in PPAR a relative gene expression in PBMN cells in the aquatic and dryland resistance training groups compared to the control group $(\mathrm{F}=15.573$, and $\mathrm{p}=0.001)$. In addition, the results of the aquatic training group indicated a larger number of insignificant changes on PPAR $\alpha$ gene expression in BPMN cells 
compared to the dryland training group $(\mathrm{p}=0.38)$. Paired-samples t-test showed a significant difference in aquatic and dryland resistance training groups regarding PPAR a gene expression in PBMN cells $(\mathrm{t}=-6.954$ and $\mathrm{p}=0.001 ; \mathrm{t}=-5.571$, and $\mathrm{p}=0.001 ;$ respectively) (Figure 1).

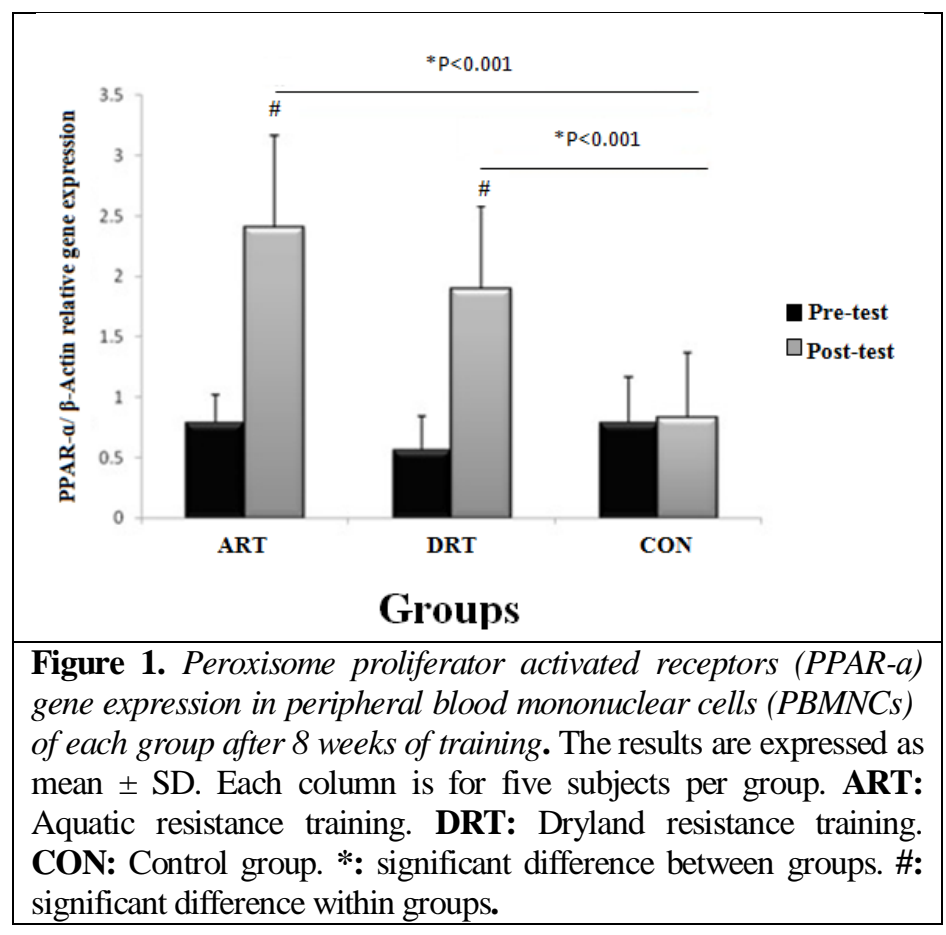

\section{DISCUSSION}

The results of the current study indicated an up-regulation of PPAR $\alpha$ gene expression among CABG patients as a result of aquatic and dryland trainings. These positive changes were significantly different from the control group. However, there were no significant differences between the two training groups. Furthermore, the results of the aquatic training group showed a larger number of insignificant changes on PPAR $\alpha$ gene expression in BPMN cells compared to the dryland training group. This could be attributed to the entertaining nature of water games or higher motivation of subjects to follow the aquatic training program.

Cardiac rehabilitation programs aim at limiting physical-psychological effects of cardiovascular disease, reducing the risk of sudden death or recurrent stroke, controlling cardiac symptoms, and stabilizing and reversing the atherosclerotic process. Although studies have reported $18 \%$ of cardiovascular problems among patients participating in a comprehensive cardiac rehabilitation program 10 years after coronary artery bypass grafting, this percentage increases to $35 \%$ among patients who refuse to participate in any rehabilitation programs (16). Studies investigating CABG patients have mostly focused on the role of physical activity in improving the quality of life through the evaluation of physical performance and muscle strength, social functioning, mental health, as well as body composition and lipid profile in these patients $(15,16,37)$. Moghadam et al. (2009) studied the effect of aerobic and resistance training on functional capacity factors, serum lipid profile, blood pressure and muscle strength during cardiac rehabilitation. The control group in this study did only aerobic exercises while the other three performed a combination of aerobic and resistance training. Due to the combined therapeutic training in that study, there was an improvement in muscle strength in addition to the statistically significant changes in the blood serum HDL levels (38). 
Afzalaghaiee et al. (2010) investigated the effect of cardiac rehabilitation on changes in blood lipid profile of Iranian men and women with coronary artery disease. Their rehabilitation program comprised 24 sessions of aerobic exercises including jogging on treadmill, pedaling on a stationary bike and arm ergometer workout, which resulted in significant changes in cholesterol factors, LDL, LDL/HDL ratio, and cholesterol/ HDL ratio (39). There has only been limited research on the effect of aquatic resistance training on reverse cholesterol transport (20) with a noticeable gap in studies which focus on the effects of such trainings on the expression of genes in patients who have undergone $\mathrm{CABG}$. As a pioneering research in the field of cardiac rehabilitation, the present study is aimed at investigating PPAR $\alpha$ gene expression in PBMN cells in middle-aged women having had $\mathrm{CABG}$, after 8 weeks of aquatic and dryland resistance training programs. As reported, the APT-dependent transporters in BPMN function as independent risk factors used for predicting atherosclerosis (14). BPMN cells were selected as the target tissue owing to the role of PPARs in the activation of ABCs (12) and the relative availability of these cells compared to other tissues. The results of the current study showed an up-regulation of PPAR $\alpha$ gene expression among CABG patients as a result of aquatic and dryland trainings. These positive changes were significantly different from the control group. However, there were no significant differences between the two training groups. In addition, the results of the aquatic training group showed a larger number of insignificant changes on PPAR $\alpha$ gene expression in BPMN cells compared to the dryland training group. This could be attributed to the entertaining nature of water games or higher motivation of subjects to follow the aquatic training program.

Previous studies have reported different responses of PPAR $\alpha$ gene expression to different exercises $(26-29,40)$. The study of Boucher et al. (2008) indicated an increased gene expression of PPAR $\gamma$ after 8 weeks of light training (26). Spangenburg et al. (2009) examined the changes in PPAR gene expression in skeletal muscles after heavy training and only observed insignificant changes in PPARs after each exercise (40). Iemitsu et al. (2002) found that exercising improves the induction of a decrease in PPAR $\alpha$ levels in the cardiac tissue of elderly mice (41). Petridou et al. (2007) investigated the effect of an 8-week optional wheel-running on the expression of various isoforms of PPAR, but did not observe any significant differences in the content of PPAR in the liver, muscle and fat tissues in the training and control groups (29). Tunstall et al. (2002) also investigated ergometer training programs (63\% of maximal oxygen uptake, lasting for 60 minutes/9 days) done by healthy men and women. However, their result is different from those of the present study since they did not find any significant changes in PPAR $\alpha$ gene expression in skeletal muscle (42). This difference could be attributed to the type, intensity or duration of the training, which failed to induce the up-regulation of Peroxisome proliferator-activated receptors. As suggested in a study, increasing protein and mRNA levels of PPAR $\alpha$ gene requires training programs of at least 6 weeks with $60 \%$ to $80 \%$ maximal oxygen uptake (27). Russel et al. (2003) reported a significant increase in PPAR $\alpha$ gene expression in skeletal muscles in men who performed 8 weeks of resistance training (27). According to Fatone et al., a combination of two-session aerobic training (55\% to $70 \%$ maximal oxygen uptake) and circuit training (60\% to $80 \%$ onerepetition maximum) results in a significant increase in PPAR $\alpha$ gene expression after 6 to 12 months, whereas PPAR $\gamma$ increased after only 6 months (43). The findings of both researches are consistent with the results of the current study.

As reported in numerous researches, PPARs regulate an extensive network of genes involved in glucose and fat metabolism. In other words, PPAR $\alpha$ regulates fatty acid transport, mitochondrial fatty acid oxidation and ketogenesis (44). Also, physical activities stimulate lipolysis and increase the levels of free fatty acids which subsequently influence the direct effect of exercising on transcription factors of metabolism (27). PPAR $\alpha$ activators decrease the availability of fatty acids to produce triglyceride rich in very low-density lipoprotein (VLDL) in the liver. Hence, the physiological role of PPAR $\alpha$ receptor is to receive the total fatty acids in the food in key tissues. PPAR $\alpha$ 
activity affects the expression of some encrypted genes for proteins involved in HDL-C metabolism. It also increases reverse cholesterol transport by accelerating the release of cholesterol from peripheral cells and cholesterol efflux in the liver which is achieved through vascular expression of HDL-C receptors, ABC-I transporters and scavenger receptor class $\mathrm{B}$ type I (SR-BI). In general, PPAR $\alpha$ affects lipid profile by increasing the production of HDL-C, accelerating the cholesterol efflux and hepatic uptake, and provides significant health benefits by increasing the protective effects of HDL-C. Furthermore, heightened activity of PPAR $\alpha$ increases the expression of lipoprotein lipase and apolipoprotein A-V (apo A-I) while it decreases the expression of apo C-III in the liver. As a result, VLDL particles are reduced, resulting in lower plasma triglyceride levels (45). In other words, PPAR $\alpha$ is known as one of the deterrents of atherosclerosis. To prevent atherogenesis, PPAR $\alpha$ agonists regulate ABCA1 in order to promote cholesterol efflux from macrophage and prevent early atherosclerosis (12). Several studies have shown that stimulating (PPAR $\alpha$ and PPAR $\gamma$ ) increases the expression of liver $\mathrm{X}$ receptor (LXR). As endogenous $\operatorname{PPAR} \alpha$ agonists, fatty acids may also be effective in increasing LXR $\alpha$ expression (46). In other words, PPAR $\alpha$ agonists stimulate the ABCA1 gene expression through the LXR pathway (47). Given that PPAR $\gamma$ activators can regulate LXR gene expression, they can also affect the levels of mRNA in ABCA1indirectly. On the other hand, PPAR $\delta$ ligands regulate ABCA1 gene expression directly and through an unknown mechanism (48). LXR ligands stimulate the expression of ABCA1, ABCG1 and ABCG4 which increase cholesterol efflux to HDLthrough reverse cholesterol transport in macrophages. LXRs also increase the transcription of apolipoproteins (apo E, apo-C in macrophages and apo-D in fatty tissue) which are cholesterol receptors. Furthermore, LXRs positively regulate lipoprotein lipase, cholesterol ester transfer protein (CETP), and phospholipid transfer protein (PLTP), which are all involved in the reconstruction of lipoprotein (49). LXR also stimulates the synthesis of bile acids through its target gene, i.e cytochrome P450, family 7 , subfamily $A$, member 1 (CYP7A1), which is the main enzyme involved in the conversion of cholesterol into bile acids (50). Therefore, as regards the increase in the expression of PPAR and LXR due to exercising, some researchers have suggested that PPAR activation will lead to the primary activation of LXR. As a result, LXR causes the up regulation and increased expression of ABCA1 and ABCG1 transporters, resulting in further reverse cholesterol transport eventually (26).

Moreover, this research was limited to the effects of regular exercises on blood cells which might be showing similar effects on fat cells, hepatic cells and other types involved in fat metabolism. In other words, the difficulty of collecting human biopsy samples and the high costs of measuring multiple parameters involved in the process of reverse cholesterol transport were among the limitations of the current study, and affected the objective of this research which was to carry out a precise and comprehensive investigation of various cellular and molecular mechanisms.

\section{CONCLUSION}

The present study showed the desirable effects of aquatic and dryland resistance training on PPARs in women who have undergone CABG previously. Both training programs proved to be beneficial if included in cardiac rehabilitation of CABG patients. Given that many people currently suffer from atherosclerosis or require $\mathrm{CABG}$, these training programs require further studies to investigate the effects of exercising on CABG patients.

\section{APPLICABLE REMARKS}

- Both types of resistance training on land and water can improve fat metabolism and some factors involved in the process of reverse cholesterol transport, the process of beneficial effects on patient recovery after coronary artery bypass surgery and therefore, this type of training is recommended on the part of the rehabilitation of the patient. 


\section{REFERENCES}

1. Gersh BJ, Sliwa K, Mayosi BM, Yusuf S. Novel therapeutic concepts: the epidemic of cardiovascular disease in the developing world: global implications. European heart journal. 2010;31(6):642-8.

2. Sintay RKM. Lived experiences of patients undergoing cardiac rehabilitation. Journal of Health Social Qualitative Section. 2011;1(1):58-70.

3. Hatchett R, Thompson DR. Cardiac Nursing: A Comprehensive Guide. 2nd ed: Elsevier Health Sciences; 2008. $674 \mathrm{p}$.

4. Jamieson M, Wilcox S, Webster W, Blackhurst D, Valois RF, Durstine JL. Factors influencing health-related quality of life in cardiac rehabilitation patients. Progress in cardiovascular nursing. 2002;17(3):124-31, 54.

5. Mann D, Zipes D, Libby P, Bonow R. Braunwald's Heart Disease: A Textbook of Cardiovascular Medicine. 10th ed: Elsevier Health Sciences; 2014. 2040 p.

6. Society Section. The heart surgery statistics in Iran are equal to China. Mental Health and Society. 2006:2 [Article in Farsi].

7. Hihi AK, Michalik L, Wahli W. PPARs: transcriptional effectors of fatty acids and their derivatives. Cellular and molecular life sciences : CMLS. 2002;59(5):790-8.

8. Feige JN, Gelman L, Michalik L, Desvergne B, Wahli W. From molecular action to physiological outputs: peroxisome proliferator-activated receptors are nuclear receptors at the crossroads of key cellular functions. Progress in lipid research. 2006;45(2):120-59.

9. Grandl M. Influence of E-LDL and Ox-LDL on the metabolism of ApoE, cholesterol, sphingolipids and glycosphingolipids as well as on the raft-composition in human macrophages. Regensburg, Germany: University of Regensburg; 2006.

10. Ghaedi K, Ghasemi S, Nasresfahani MH, Esmaeili A, Tanhaei S, Rabiei F, et al. Cloning Of Mouse Ppary1 Cdna In Pegfp-C1 Expression Vector. Research Journal Of University Of Isfahan "Science". 2008;35(6):181-94 [Article in Farsi].

11. Campbell FM, Kozak R, Wagner A, Altarejos JY, Dyck JR, Belke DD, et al. A role for peroxisome proliferatoractivated receptor alpha (PPARalpha) in the control of cardiac malonyl-CoA levels: reduced fatty acid oxidation rates and increased glucose oxidation rates in the hearts of mice lacking PPARalpha are associated with higher concentrations of malonyl-CoA and reduced expression of malonyl-CoA decarboxylase. The Journal of biological chemistry. 2002;277(6):4098-103.

12. Srivastava N. ATP binding cassette transporter A1--key roles in cellular lipid transport and atherosclerosis. Molecular and cellular biochemistry. 2002;237(1-2):155-64.

13. Ghanbari-Niaki A. Treadmill exercise training enhances ATP-binding cassette protein-A1 (ABCA1) expression in male rats' heart and gastrocnemius muscles. International journal of endocrinology and metabolism. 2010;8(4):206-10.

14. Rashidlamir A. Investigation of the Effect of Aerobic and Resistance Exercises on Peripheral Blood Mononuclear Cells ABCG1 Gene Expression in Female Athletes. The Journal of Shahid Sadoughi University of Medical Sciences. 2012;20(1):1-9 [Article in Farsi].

15. Gaeini AA, Sattarifard S, CafiZadeh S, Nejatian M. The comparison of eight weeks of combined and aerobic training on functional capacity, body composition and strength in post-coronary artery bypass graft cardiac patients. Cardiovascular Nursing Journal. 2013;2(1):34-41 [Article in Farsi].

16. Siavoshi S, Roshandel M, Zareiyan A, Ettefagh L. The effect of cardiac rehabilitation care plan on the quality of life in patients undergoing coronary artery bypass graft surgery. Cardiovascular Nursing Journal. 2012;1(2):38-46 [Article in Farsi].

17. Dalir Z, Vahdat Feizabadi E, Mazlom S, Rajaee Khorasani A. The Effect of short-term cardiac rehabilitation program on anxiety and depression in patients after coronary artery bypass surgery. Evidence Based Care. 2013;3(3):33-42 [Article in Farsi].

18. Nazari N, Hashemi-Javaheri AA, Rashid-Lamir A, Alaviniya E. Effect of Cardiac Rehabilitation on Strength and Balance in Patients after Coronary Artery Bypass Graft. Zahedan Journal of Research in Medical Sciences. 2014;16(1):74-8.

19. Dakei Z, Hemmat Far A, Azizbeigi k. Effect of resistance and endurance training protocols on functional capacity and quality of life in male patients after myocardial infarction. Cardiovascular Nursing Journal. 2014;3(1):26-33 [Article in Farsi].

20. Volaklis KA, Spassis AT, Tokmakidis SP. Land versus water exercise in patients with coronary artery disease: effects on body composition, blood lipids, and physical fitness. American heart journal. 2007;154(3):560.e1-6. 
21. Malekzadeh m, Ghasemi b, Mirnasuri r. Effect of aquatic exercises on the motor performance and the quality of life in patients with knee joint osteoarthritis. Hormozgan Medical Journal. 2014;18(3):194-200 [Article in Farsi].

22. Etesami AS, Zamani J, Zolaktaf V, Ghasemi G. Effectiveness of Aquatic Exercise Therapy on the Quality of Life in Women With Knee Osteoarthritis. Iranian Journal of Ageing. 2015;10(3):62-71 [Article in Farsi].

23.Zendehboodi M, Behzadni B, Mazarei E. Comparison of the effect of hydrotherapy and physiotherapy methods in rate of kneeahce, matinal dryness, daily activities, athletic performance, and recreation activities in athletes men with knee osteoarthritis. Journal of Practical Studies at Biosciences in Sport. 2014;1(2):95-109 [Article in Farsi].

24. Dressel U, Allen TL, Pippal JB, Rohde PR, Lau P, Muscat GE. The peroxisome proliferator-activated receptor beta/delta agonist, GW501516, regulates the expression of genes involved in lipid catabolism and energy uncoupling in skeletal muscle cells. Molecular endocrinology (Baltimore, Md). 2003;17(12):2477-93.

25. Hardwick JP, Osei-Hyiaman D, Wiland H, Abdelmegeed MA, Song B-J. PPAR/RXR Regulation of Fatty Acid Metabolism and Fatty Acid $\omega$-Hydroxylase (CYP4) Isozymes: Implications for Prevention of Lipotoxicity in Fatty Liver Disease. PPAR Research. 2009;2009:952734.

26. Butcher LR, Thomas A, Backx K, Roberts A, Webb R, Morris K. Low-intensity exercise exerts beneficial effects on plasma lipids via PPARgamma. Med Sci Sports Exerc. 2008;40(7):1263-70.

27. Russell AP, Feilchenfeldt J, Schreiber S, Praz M, Crettenand A, Gobelet C, et al. Endurance training in humans leads to fiber type-specific increases in levels of peroxisome proliferator-activated receptor-gamma coactivator-1 and peroxisome proliferator-activated receptor-alpha in skeletal muscle. Diabetes. 2003;52(12):2874-81.

28. Ghanbari-Niaki A, Ghanbari-Abarghooi S, Rahbarizadeh F, Zare-Kookandeh N, Gholizadeh M, Roudbari F, et al. Heart ABCA1 and PPAR- $\alpha$ Genes Expression Responses in Male rats: Effects of High Intensity Treadmill Running Training and Aqueous Extraction of Black Crataegus-Pentaegyna. Research in Cardiovascular Medicine. 2013;2(4):153-9.

29. Petridou A, Tsalouhidou S, Tsalis G, Schulz T, Michna H, Mougios V. Long-term exercise increases the DNA binding activity of peroxisome proliferator-activated receptor gamma in rat adipose tissue. Metabolism: clinical and experimental. 2007;56(8):1029-36.

30. Chen VCW, Lee CW, Bui S, Lee T, Fluckey J, Riechman S. Skeletal Muscle PPAR-delta increases with 10 Weeks of Resistance Training (LB819). The FASEB Journal. 2014;28(1_supplement):LB819.

31. Chen VC, Lee CW, Bui S, Lee TV, Riechman SE. Skeletal Muscle PPAR $\delta$ Increases Acutely with Resistance Exercise Inversely Proportional to Body Fat Percentage. The FASEB Journal. 2016;30(1_supplement):lb708-lb.

32. Ghorbanian B, Ravassi A, Kordi MR, Hedayati M. The Effects of Rope Training on Lymphocyte ABCA1 Expression, Plasma ApoA-I and HDL-c in Boy Adolescents. International journal of endocrinology and metabolism. 2013;11(2):76-81.

33. Rashidlamir A, Ghanbari-Niaki A, Saadatnia A. The Effect of Eight Weeks of Wrestling and Wrestling Technique Based Circuit Trainingon Lymphocyte ABCA1 Gene Expression and Plasma Apolipoprotein A-I. World Journal of Sport Sciences. 2011;4(2):144-50.

34. Amirsasan R, Khaleghi-Anbardan M-M, Zarghami Khameneh A. The acute effects of exhaustive resistance training and different dosages of caffeine intake on IL-6 response. Razi Journal of Medical Sciences. 2015;22(134):49-58 [Article in Farsi].

35. Ghanbari Niaki A, Ghanbari Abarghooi S, Gholizadeh M. Heart ATP-Binding Cassette Protein A1 and G1, Peroxisome Proliferator-Activated Receptor- $\alpha$ and Liver X Receptors Genes Expression in Response to Intensive Treadmill Running and Red $<\mathrm{i}>$ Crataegus pentaegyna $</ \mathrm{i}>$ (Sorkh valik) in Male Rats. Zahedan Journal of Research in Medical Sciences. 2015;17(5).

36. Livak KJ, Schmittgen TD. Analysis of relative gene expression data using real-time quantitative PCR and the 2(Delta Delta C(T)) Method. Methods. 2001;25(4):402-8.

37. Fallahi AA, Gaeini AA, Kordi MR, Nejatian M, Etemadi S. The Effects Of Continuous And Interval Exercise Training On Quality Of Life In Heart Patients After Coronary Artery Bypass Graft Surgery (CABG). Sport Biosciences. 2011(10):115-29 [Article in Farsi].

38. Moghadam BA, Tavakol K, Hadian MR, Bagheri H, Jalaei S. Phase III cardiac rehabilitation after CABG: Combined aerobic and strengthening exercise protocols. International Journal of Therapy and Rehabilitation. 2009;16(8):420-30.

39. Afzalaghaiee E, Hadian MR, Attarbashi Moghadam B, Tavakol K, Zandparsa AF, Jalaei S, et al. The Effects Of Cardiac Rehabilitation On Changes In The Lipid Profile Of Iranian male and female With Coronary Artery Disease Refered To Emam Khomeini Hospital Complex. Modern Rehabilitation. 2010;4(1-2):45-9 [Article in Farsi]. 
40. Spangenburg EE, Brown DA, Johnson MS, Moore RL. Alterations in peroxisome proliferator-activated receptor mRNA expression in skeletal muscle after acute and repeated bouts of exercise. Molecular and cellular biochemistry. 2009;332(1-2):225-31.

41. Iemitsu M, Miyauchi T, Maeda S, Tanabe T, Takanashi M, Irukayama-Tomobe Y, et al. Aging-induced decrease in the PPAR-alpha level in hearts is improved by exercise training. American journal of physiology Heart and circulatory physiology. 2002;283(5):H1750-60.

42. Tunstall RJ, Mehan KA, Wadley GD, Collier GR, Bonen A, Hargreaves M, et al. Exercise training increases lipid metabolism gene expression in human skeletal muscle. American journal of physiology Endocrinology and metabolism. 2002;283(1):E66-72.

43. Fatone C, Guescini M, Balducci S, Battistoni S, Settequattrini A, Pippi R, et al. Two weekly sessions of combined aerobic and resistance exercise are sufficient to provide beneficial effects in subjects with Type 2 diabetes mellitus and metabolic syndrome. Journal of endocrinological investigation. 2010;33(7):489-95.

44. Vanden Heuvel JP. Diet, fatty acids, and regulation of genes important for heart disease. Current atherosclerosis reports. 2004;6(6):432-40.

45. Singh MP, Pathak D, Sharma GK, Sharma C. Peroxisome proliferator-activated receptors (PPARS): a target with a broad therapeutic potential for human diseases: an overview. Pharmacologyonline. 2011;2:58-89.

46. Wojcicka G, Jamroz-Wisniewska A, Horoszewicz K, Beltowski J. Liver X receptors (LXRs). Part I: structure, function, regulation of activity, and role in lipid metabolism. Postepy higieny i medycyny doswiadczalnej (Online). 2007;61:736-59.

47. Ghanbari-Niaki A, Rahmati- Ahmadabad S, Zare- Kookandeh N. ABCG8 Gene Responses to 8 Weeks Treadmill Running With or Without Pistachia atlantica (Baneh) Extraction in Female Rats. International journal of endocrinology and metabolism. 2012;10(4):604-10.

48. Hoekstra M, Kruijt JK, Van Eck M, Van Berkel TJ. Specific gene expression of ATP-binding cassette transporters and nuclear hormone receptors in rat liver parenchymal, endothelial, and Kupffer cells. The Journal of biological chemistry. 2003;278(28):25448-53.

49. Gabbi C, Warner M, Gustafsson JA. Minireview: liver X receptor beta: emerging roles in physiology and diseases. Molecular endocrinology (Baltimore, Md). 2009;23(2):129-36.

50. Cote I, Ngo Sock ET, Levy E, Lavoie JM. An atherogenic diet decreases liver FXR gene expression and causes severe hepatic steatosis and hepatic cholesterol accumulation: effect of endurance training. European journal of nutrition. 2013;52(5):1523-32. 